\title{
Effect of strain rate on $\alpha$-lath thickness of TC17 alloy after deformation and subsequent heat treatment
}

\author{
Zimin Lu, Jiao Luo*, Miaoquan Li \\ School of Materials Science and Engineering, Northwestern Polytechnical University, Xi'an, 710072, P.R. China \\ *Corresponding author, Tel. +8629 88460465, E-mail: luojiao@nwpu.edu.cn
}

\begin{abstract}
Effect of strain rate on $\alpha$-lath thickness of TC17 alloy with a basketweave microstructure was studied in the present work. For this purpose, this alloy was deformed in the $\beta$ phase region and subsequently soluted and aged in $\alpha+\beta$ phase region. Moreover, optical micrograph (OM) and electron backscatter diffraction (EBSD) were applied to analyze the change of lath thickness at different strain rates. The result showed that $\alpha$-lath thickness increased with increasing strain rate. This phenomenon was possibly attributed to the higher degree of variant selection (DVS) at higher strain rate $\left(0.1 \mathrm{~s}^{-1}\right)$. The higher DVS was beneficial for the formation of parallel $\alpha$ lath colonies during cooling after deformation. And, these parallel $\alpha$-lath colonies would more easily grow up and coarsen during subsequent heat treatment. Therefore, $\alpha$-lath at higher strain rate is more thick.
\end{abstract}

Keywords: TC17 alloy, Basketweave microstructure, $\alpha$-lath thickness, Electron backscattered diffraction

\section{Introduction}

In aviation industry, it is difficult to avoid crack initiation in the workpieces withstanding cyclic stress at high temperature, but developing the toughness during crack growth is reliable. Therefore the requirements for better damage tolerance properties of titanium alloys is increasing [1]. Basketweave microstructure of two phase titanium alloys has high fracture toughness and shows superior resistance to creep and fatigue crack growth [2]. Therefore, numerous researchers focused on studying the relationship between microstructural features and fracture toughness in basketweave microstructure, because fracture toughness was one of significant indexes that reflected damage tolerance properties. It is agreed that increasing $\alpha$-lath thickness can enhance the fracture toughness of titanium alloys with a basketweave microstructure [3-5]. So, the effects of processing parameters on $\alpha$-lath thickness have received considerable attentions.

For instance, Behera et al. [6] reported a decrease in $\alpha$-lath thickness with increasing cooling rate when Ti-5Ta-1.8Nb alloy was cooled from $\beta$ phase field. Xu et al. [7] investigated the evolution of lamellar microstructure in Ti-17 alloy during heat treatment and found an increase of $\alpha$-lath thickness after heat treatment. He et al. [8] showed that a moderate increase of height reduction resulted in the increase of $\alpha$-lath thickness in basketweave microstructure of BT-25 titanium alloy, but further increase of height reduction induced the globularization of $\alpha$-laths. Semiatin et al. [9] indicated that $\alpha$-lath thickness of Ti-6Al-4V increased with increasing deformation temperature. Shi et al. [10] indicated the $\alpha$-lath thickness decreased with increasing cooling rate and increased with increasing aging temperature in TC21 alloy with a basketweave microstructure. 
However, few studies focus on the effect of strain rate on $\alpha$-lath size in titanium alloys with a basketweave microstructure. Hence, this objective is to investigate the effect of strain rate on $\alpha$-lath thickness in basketweave microstructure. For this purpose, the $\alpha$ lath thickness is measured via quantitative metallography image analysis software. Characterization techniques include optical microscopy (OM) and high-resolution electron backscatter diffraction (EBSD).

\section{Material and experimental procedures}

In the present work, as-received TC17 alloy with an equiaxed microstructure was used. The chemical composition (in wt\%) of this alloy was $5.12 \mathrm{Al}, 2.03 \mathrm{Sn}, 2.10 \mathrm{Zr}, 4.04 \mathrm{Mo}, 3.94 \mathrm{Cr}, 0.10 \mathrm{Fe}, 0.012 \mathrm{C}, 0.007 \mathrm{~N}, 0.007 \mathrm{H}, 0.12 \mathrm{O}$ and balance Ti. The $\beta$ transus temperature of $\mathrm{TC} 17$ alloy was approximately $905^{\circ} \mathrm{C}[11]$.

Cylindrical specimens with the dimension of $\Phi 8 \mathrm{~mm} \times 12 \mathrm{~mm}$ were isothermally compressed via a Gleeble-3500 thermomechanical simulator. Before compression, specimens were heated at $10^{\circ} \mathrm{C} \cdot \mathrm{s}^{-1}$ through Electrical Resistance Heating (ERH), and held for $0.5 \mathrm{~h}$ at a given deformation temperature. Isothermal compression was performed at a deformation temperature of $910^{\circ} \mathrm{C}$, a height reduction of $40 \%$ and strain rates of $0.001 \mathrm{~s}^{-1}, 0.01 \mathrm{~s}^{-1}$ and $0.1 \mathrm{~s}^{-1}$. After compression, the deformed specimens were subjected to furnace cooling (FC) at a cooling rate of $36^{\circ} \mathrm{C} \cdot \mathrm{min}^{-1}$ to $600^{\circ} \mathrm{C}$ and air cooling (AC) to room temperature. During compression, the surface of each specimen was welded a thermocouple to measure temperature.

Following isothermal compression, all specimens were soluted and aged treatment via a KSL1400X-A4 box-type furnace. The solution treatment was conducted at $800^{\circ} \mathrm{C}$ for $4 \mathrm{~h}$, and cooled in water to room temperature. The aging treatment was performed at $630^{\circ} \mathrm{C}$ for $8 \mathrm{~h}$, and cooled in air to room temperature.

After that, the specimens were axially sectioned and used for OM and EBSD observations in the central region (i.e. most highly deformed). For OM observation, the specimens were mechanically polished and chemically etched in a solution of $\mathrm{HF}: \mathrm{HNO}_{3}: \mathrm{H}_{2} \mathrm{O}=$ 10: 15: 75. A Leica DMI3000M optical microscope was used to take optical micrographs. The optical micrographs was perpendicular to the compression direction. The $\alpha$-lath thickness was measured using Image pro-plus 6.0 software (IPP) and was calculated by the average value of five visual fields.

For EBSD observation, the specimens were mechanically polished and electro-polished in a solution of $\mathrm{CH}_{3} \mathrm{OH}$ : $\mathrm{CH}_{3}\left(\mathrm{CH}_{2}\right)_{3} \mathrm{OH}: \mathrm{HClO}_{4}=64: 30: 6$ with 20 volts voltage for 40 seconds. A Carl Zeiss Merlin Compact high resolution field emission scanning electron microscope (SEM) was used to carry out EBSD observation and the EBSD scans were taken along the direction perpendicular to the compression axis with a step size of $0.08 \mu \mathrm{m}$. A HKL Channel 5 software was used to analysis EBSD data.

\section{Results and discussion}

As above-mentioned in section 2, the isothermally compressed specimens at strain rates of $0.001 \mathrm{~s}^{-1}, 0.01 \mathrm{~s}^{-1}$ and $0.1 \mathrm{~s}^{-1}$ were soluted at $800^{\circ} \mathrm{C} / 4 \mathrm{~h}$ and aged at $630^{\circ} \mathrm{C} / 8 \mathrm{~h}$. And, corresponding microstructure at different strain rates was shown in Fig. 1. It is observed in Fig. 1 that the microstructure are all composed of intersected $\alpha$-laths and $\beta$ phase as marked with yellow arrows, which is a typical of basketweave microstructure. As TC17 alloy is a near $\beta$ alloy, the martensitic phase transformation is dominant during the $\beta \rightarrow \alpha$ 
transformation when the deformed specimens were cooled in a medium cooling rate $\left(36^{\circ} \mathrm{C} \cdot \mathrm{min}^{-1}\right)$. It resulted in that the most of secondary $\alpha$ phase precipitated in the $\beta$ grain interior and were plate-like or acicular. Moreover, these $\alpha$-laths have 12 possible orientations due to Burgers relationship. The large number of possible orientations results in multiple repetitions of the $\alpha$-lath orientations. Thus, a microstructure similar to the basket with weave pattern appears as shown in Fig. 1. Some coarse and parallel $\alpha$ laths, marked with red arrows and circles, are also observed in Fig. 1a-c. Compared Fig. 1c to Fig. 1a, it is seen that the amount of coarse $\alpha$-laths increase remarkably at higher strain rate $\left(0.1 \mathrm{~s}^{-1}\right)$. In the present work, the $\alpha$-lath thickness at different strain rates was measured using IPP and shown in Table 1. It is seen that the $\alpha$-lath thickness at a strain rate of $0.001 \mathrm{~s}^{-1}$ is $447 \pm 15 \mathrm{~nm}$. When the strain rate is up to $0.1 \mathrm{~s}^{-1}$, it increases to $472 \pm 33 \mathrm{~nm}$. This implies that the $\alpha$-lath thickness slightly increases with increasing strain rate. This phenomenon can be reasonably explained by the two combined aspects: (i) the rate of dislocation accumulation; and (ii) the degree of variant selection (DVS). Detailed description on the $\alpha$-lath coarsening is given in the following section..
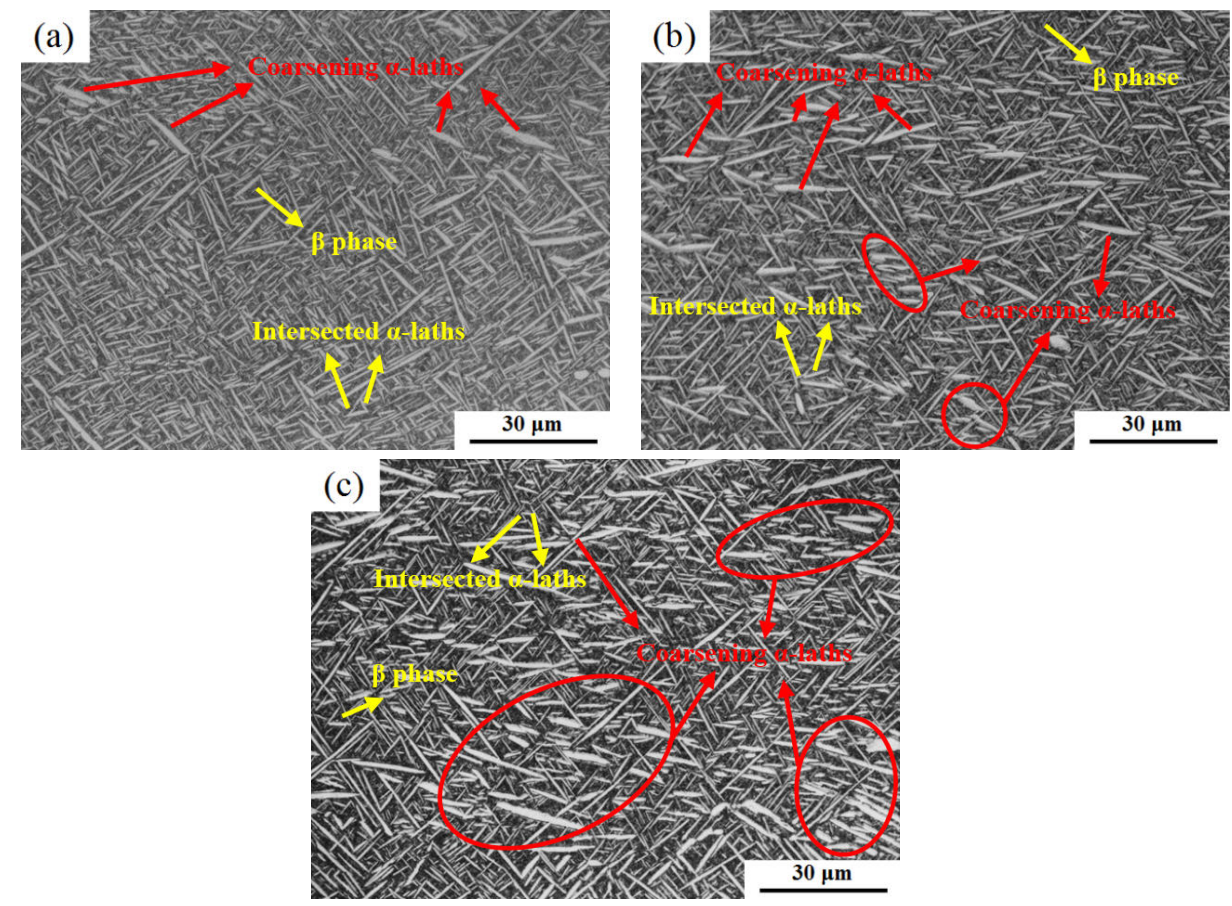

Fig. 1 Effect of strain rate on microstructure of $\mathrm{TC} 17$ alloy after deformation and subsequent heat treatment $\left(910^{\circ} \mathrm{C}, 40^{\circ}, 36^{\circ} \mathrm{C} \cdot \mathrm{min}^{-1}\right.$, $800^{\circ} \mathrm{C} / 4 \mathrm{~h}+\mathrm{WQ}, 630^{\circ} \mathrm{C} / 8 \mathrm{~h}+\mathrm{AC}$ ): (a) $0.001 \mathrm{~s}^{-1}$; (b) $0.01 \mathrm{~s}^{-1}$; (c) $0.1 \mathrm{~s}^{-1}$

Table 1 Effect of strain rate on $\alpha$-lath thickness of TC17 alloy after deformation and subsequent heat treatment 


\begin{tabular}{|c|c|c|c|c|c|}
\hline $\begin{array}{l}\text { Deformation } \\
\text { temperature } \\
\left({ }^{\circ} \mathrm{C}\right)\end{array}$ & $\begin{array}{c}\text { Height } \\
\text { reduction (\%) }\end{array}$ & $\begin{array}{l}\text { Cooling rate } \\
\left({ }^{\circ} \mathrm{C} \cdot \mathrm{min}^{-1}\right)\end{array}$ & $\begin{array}{c}\text { Solution and } \\
\text { aging treatment }\end{array}$ & Strain rate $\left(\mathrm{s}^{-1}\right)$ & $\begin{array}{l}\alpha \text {-lath thickness } \\
\text { (nm) }\end{array}$ \\
\hline \multirow{3}{*}{910} & \multirow{3}{*}{40} & \multirow{3}{*}{36} & & 0.001 & $447 \pm 15$ \\
\hline & & & $\begin{array}{c}800^{\circ} \mathrm{C} / 4 \mathrm{~h}+\mathrm{WQ}, \\
630^{\circ} \mathrm{C} / 8 \mathrm{~h}+\mathrm{AC}\end{array}$ & 0.01 & $464 \pm 17$ \\
\hline & & & & 0.1 & $472 \pm 33$ \\
\hline
\end{tabular}

Inverse pole figure (IPF) maps of $\alpha$ phase at different strain rates are shown in Fig. 2a, 2c and 2e. The deformed specimens of TC17 alloy is heat-treated in the following procedures: the solution treatment was conducted at $800^{\circ} \mathrm{C}$ for $4 \mathrm{~h}$, and the aging treatment was performed at $630^{\circ} \mathrm{C}$ for $8 \mathrm{~h}$. Fig. $2 \mathrm{~b}, 2 \mathrm{~d}$ and $2 \mathrm{f}$ show the distribution of grain boundary misorientation for $\alpha$ phase. In the present work, grain boundaries with a misorientation range of $2^{\circ} \sim 15^{\circ}$ are considered low angle boundaries (LABs) and the misorientation range of high angle boundaries (HABs) is more than $15^{\circ}$. LABs are outlined by fine white lines and HABs of $\alpha$ phase and $\beta$ phase are outlined by thick black lines and thick blue lines, respectively. In Fig. 2a, 2c and 2e, it is easy to observe that the parallel $\alpha$-laths almost show the same orientation and intersected $\alpha$-laths with different orientations are separated by HABs. Meanwhile, it is seen in Fig. $2 \mathrm{~b}, 2 \mathrm{~d}$ and $2 \mathrm{f}$ that the misorientation angle of less than $2^{\circ}$ gradually increases with increasing strain rate. It indicates that more parallel $\alpha$-lath colony are present at higher strain rates $\left(0.1 \mathrm{~s}^{-1}\right)$. Fig. $2 \mathrm{~b}, 2 \mathrm{~d}$ and $2 \mathrm{f}$ also reveal that misorientation angles mainly distribute around $0^{\circ}, 10^{\circ}, 30^{\circ}$, $60^{\circ}$ and $90^{\circ}$. Previous study [12] had reported that if variant selection didn't happen, there would be six possible misorientations expressed as axis/angle pairs between two different $\alpha$ variants, including $0^{\circ}, 10.53^{\circ}, 60^{\circ}, 60.83^{\circ}, 63.26^{\circ}$ and $90^{\circ}$. Table 2 shows these misorientations and the corresponding probabilities $\left(P_{\text {random }}\right)$ [13]. Obviously, the frequency of misorientations of $0^{\circ}, 60^{\circ}$ and $90^{\circ}$ shown in Fig. $2 \mathrm{~b}, \mathrm{~d}$ and $\mathrm{f}$ are different with the probabilities of misorientations of $0^{\circ}, 60^{\circ}$ and $90^{\circ}$ shown in Table 2 . It can be deduced that variant selection actually occurs in these specimens. Further, degree of variant selection (DVS) was introduced by Qiu et al. [14] as follows:

$$
D V S=\sum_{i=1}^{6}\left|P_{o b}(i)-P_{\text {random }}(i)\right|
$$

where $P_{\mathrm{ob}}(i)$ is the probabilities of misorientation types from actual observation and $P_{\text {random }}(i)$ is the probabilities of misorientation types without variant selection.

However, the misorientations distributing around $60^{\circ}, 60.83^{\circ}$ and $63.26^{\circ}$ are barely to distinguish. Due to this, the six possible misorientation types are simplified to be four types in the present work, including $0^{\circ}, 10.53^{\circ}, 60^{\circ}$ and $90^{\circ}$. Thus, Eq. (1) is rewritten as follows:

$$
D V S=\sum_{i=1}^{4}\left|P_{o b}(i)-P_{\text {random }}(i)\right|
$$

Then, DVS of specimens at different strain rates is calculated via Eq. (2). Table 3 shows that DVS increases with increasing strain rate. The main reason is that high strain rate will promote the rate of dislocation multiplication. Firstly, high dislocation density promoted many nucleation sites for secondary $\alpha$ phase and it refined $\alpha$-lath in a way. Secondly, high dislocation density resulted in variant selection [14-15]. Thus, more parallel $\alpha$-lath colony are present at higher strain rates $\left(0.1 \mathrm{~s}^{-1}\right)$. Moreover, it is seen that some 
parallel $\alpha$-laths have a trend to coalesce to be a thicker lath as marked with black circles in Fig. 2a, 2c and 2e. The coalescence almost occurs in every parallel $\alpha$-lath colony no matter what orientation is. Thus, it is easy to deduce that high strain rate leads to high DVS and finally results in the more remarkable growth and coalesce. This is consistent with the above description in Fig. 1. Similarly, Furuhara and Maki [16] reported that the $\alpha$ phase precipitated in a slip band would grow and coalesce to form thicker $\alpha$-laths after prolonged aging due to high degree of variant selection. In a word, $\alpha$-lath thickness is affected by both refining caused by more nucleation sites for secondary $\alpha$ phase and coarsening caused by coalescence of parallel $\alpha$-laths. And it is seemed that coarsening of $\alpha$-laths caused by coalescence of parallel $\alpha$-laths is dominant during heat treatment. So $\alpha$-lath thickness increases with increasing strain rate.
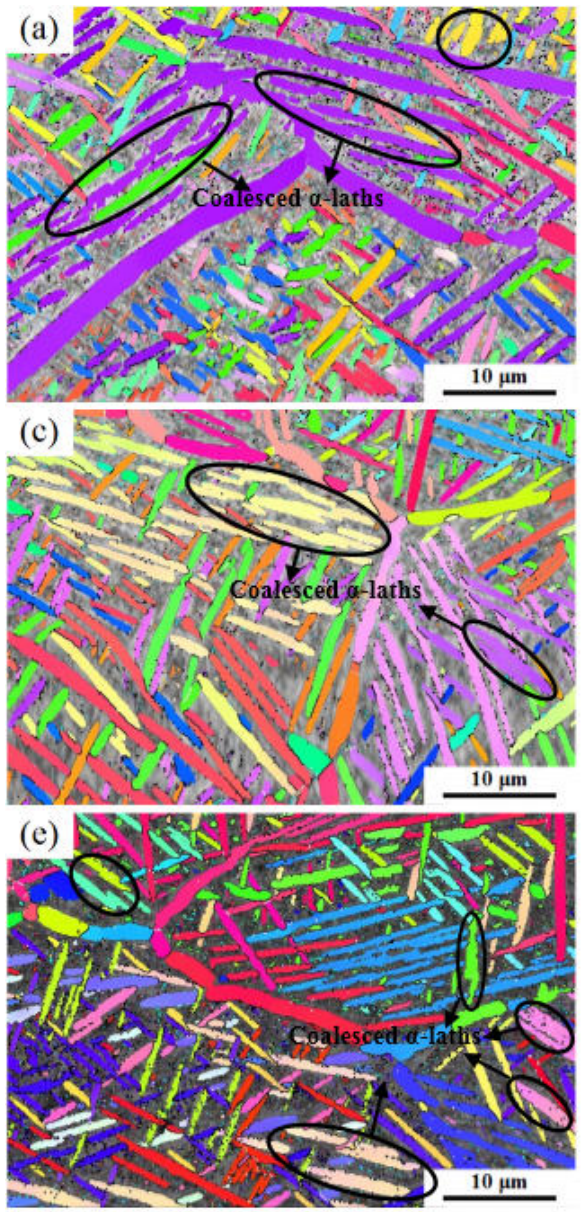

(b)

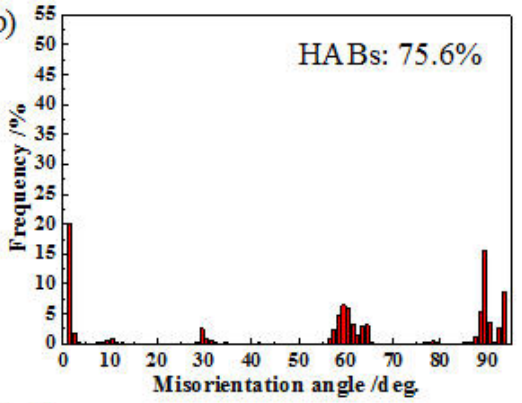

(d)

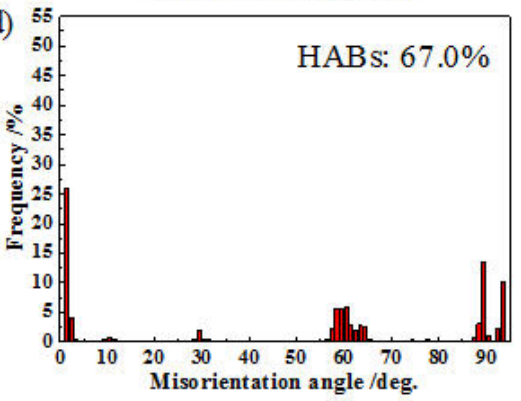

(f)

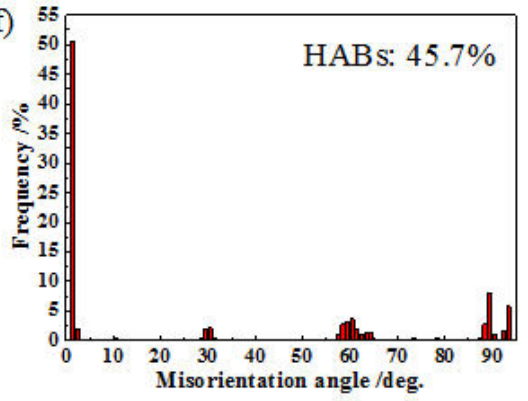

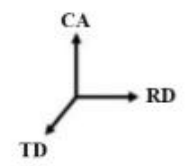<smiles>CC1[C@H](C)C[C@H]1C</smiles> 
Fig. 2 (a, $\mathrm{c}, \mathrm{e})$ Inverse pole figures (//CA) of $\alpha$ phase and $(\mathrm{b}, \mathrm{d}, \mathrm{f})$ distribution of grain boundary misorientations for $\alpha$ phase of TC17 alloy after deformation and subsequent heat treatment $\left(910^{\circ} \mathrm{C}, 40 \%, 36^{\circ} \mathrm{C} \cdot \mathrm{min}^{-1}, 800^{\circ} \mathrm{C} / 4 \mathrm{~h}+\mathrm{WQ}, 630^{\circ} \mathrm{C} / 8 \mathrm{~h}+\mathrm{AC}\right):(\mathrm{a}, \mathrm{b}) 0.001 \mathrm{~s}^{-1} ;(\mathrm{c}, \mathrm{d}) 0.01 \mathrm{~s}^{-1} ;(\mathrm{e}$,

$$
\text { f) } 0.1 \mathrm{~s}^{-1}
$$

Table 2 Types of misorientations between different a variants and the corresponding probabilities without variant selection [13]

\begin{tabular}{lll}
\hline Misorientation types & Rotation Axis/angle & $P_{\text {random }}(\%)$ \\
\hline A & I $\left(0^{\circ}\right.$, identity $)$ & 8.3 \\
B & {$[0001] / 10.53^{\circ}$} & 8.3 \\
C & {$[11-20] / 60^{\circ}$} & 16.6 \\
D & {$[10-7173] / 60.83^{\circ}$} & 33.3 \\
E & {$[10553] / 63.26^{\circ}$} & 16.6 \\
F & {$[717100] / 90^{\circ}$} & 16.6 \\
\hline
\end{tabular}

Table 3 Effect of strain rate on degree of variant selection of TC17 alloy after deformation and subsequent heat treatment $\left(910^{\circ} \mathrm{C}, 40 \%\right.$,

\begin{tabular}{cc}
\multicolumn{2}{c}{$\left.\mathbf{3 6}^{\circ} \mathbf{C} \cdot \mathbf{m i n}^{-\mathbf{1}}, \mathbf{8 0 0}{ }^{\circ} \mathbf{C} / \mathbf{4 h}+\mathbf{W Q}, \mathbf{6 3 0}{ }^{\circ} \mathbf{C} / \mathbf{8 h}+\mathbf{A C}\right)$} \\
\hline Strain rate $\left(\mathrm{s}^{-1}\right)$ & Degree of variant selection \\
\hline 0.001 & 4.17 \\
0.01 & 4.76 \\
0.1 & 5.28 \\
\hline
\end{tabular}

\section{Conclusions}

In the present work, effect of strain rate on $\alpha$-lath thickness of TC17 alloy after deformation in the $\beta$ phase region and subsequent heating treatment is discussed with the help of OM and EBSD observations. The following conclusions are obtained from this study.

(1) It is shown that the amount of coarse $\alpha$-laths increases remarkably at higher strain rate $\left(0.1 \mathrm{~s}^{-1}\right)$ and $\alpha$-lath thickness increases slightly with increasing strain rate.

(2) With increasing strain rate, $\alpha$-lath thickness is mainly affected by coarsening caused by coalescence of parallel $\alpha$-laths, rather than refining caused by more nucleation sites for secondary $\alpha$ phase.

\section{Acknowledgements}

This research was supported through research grant from National Natural Science Foundation of China (51575446). Dr. J. Luo is the Program Manager for the grant. The financial support is gratefully acknowledged.

\section{$\underline{\text { References }}$}


[1] R.R. Boyer, Mater. Sci. Eng. A 213 (1996) 103-114.

[2] C. Leyens, M. Peters, Titanium and Titanium Alloys. Fundamentals and Applications, Weinheim: Wiley-VCH, 2003.

[3] X.H. Shi, W.D. Zeng, Q.Y. Zhao, Mater. Sci. Eng. A 636 (2015) 543-550.

[4] A. Ghosh, S. Sivaprasad, A. Bhattacharjee, S. Kar, Mater. Sci. Eng. A 568 (2013) 61-67.

[5] J.K. Fan, J.S. Li, H.C. Kou , K. Hua, B. Tang, Mater. Charact. 96 (2014) 93-99.

[6] M. Behera, R. Mythili, S. Raju, S. Saroja, J. Alloys Compd. 553 (2013) 59-68.

[7] J.W. Xu, W.D. Zeng, X. Sun, Z.Q. Jia, J.H. Zhou, J. Alloys Compd. 631 (2015) 248-254.

[8] S.T. He, W.D. Zeng, J.W. Xu, Wei Chen, Mater. Sci. Eng. A 745 (2019) 203-211.

[9] S.L. Semiatin, T.R. Bieler, Acta Mater. 49 (2001) 3565-3573.

[10] Z.F. Shi, H.Z. Guo, J.W. Zhang, J.N. Yin, Trans. Nonferrous Met. Soc. China 28 (2018) 2440-2448.

[11] J. Luo, P. Ye, W.C. Han, M.Q. Li, Mater. Des. 146 (2018) 152-162.

[12] S. Wang, M. Aindow, M. Starink, Acta Mater. 51 (2003) 2485-2503.

[13] D. Qiu, R. Shi, D. Zhang, W. Lua, Y. Wang, Acta Mater. 88 (2015) 218-231.

[14] S. Xu, L.S. Toth, C. Schuman, J. Lecomte, M.R. Barnett, Acta Mater. 124 (2017) 59-70.

[15] N. Gey, M. Humbert, H. Moustahfid, Scripta Mater. 42(6) (2000) 525-530.

[16] T. Furuhara, T. Maki, Mater. Sci. Eng. A 312(1) (2001) 145-154. 